\title{
Comportement alimentaire de chèvres pâturant une suberaie emmaquisée
}

\author{
JP Goby, JJ Rochon

\begin{abstract}
Laboratoire des agroressources méditerranéennes, université de Perpignan, chemin de la Passio-Viella, 66025 Perpignan, France
\end{abstract}

La compréhension du comportement alimentaire de chèvres utilisant une suberaie envahie par le maquis permet de gérer leur pâturage sur ce territoire afin à la fois de mieux les nourrir et d'entretenir des zones sensibles aux incendies.

Les observations sont réalisées sur un troupeau de 60 chèvres laitières de race Alpine chamoisée et Saanen, en piémont du massif des Albères (Pyrénées-Orientales). Ces animaux pâturent des parcs clóturés formés d'une partie non débroussaillée, et d'une zone débroussaillée et enherbée. La composition de la ration prélevée et les quantités ingérées sont estimées par la méthode des coups de dents (Bourbouze, 1980) sur un échantillon de 12 chèvres. Trois chèvres issues du troupeau ont été équipées de fistules ruminales. L'évolution de la dégradabilité dans le rumen des 2 aliments ligneux les plus consommés (Erica arborea, Quercus suber) est suivie selon la méthode in sacco (Demarquilly et Chenost, 1969). Le témoin utilisé est la paille traitée à l'ammoniaque. Les mesures ont été répétées 4 fois en relation avec les modifications de la ration : en automne au début (novembre) et à la fin (décembre) de l'exploitation d'un parc emma. quisé avec des bruyères arborescentes, chêneslièges et autres, et pauvre en plantes herbacées ; en mars après la chute des glands ; en mai avec une offre diversifiée d'aliments d'origine arbustive et herbacée.

Pendant la période de chute des glands ou de croissance rapide de l'herbe, les animaux consomment ces ressources de qualité de préférence aux aliments plus lignifiés. Les quantités ingérées sont importantes (tableau I). Avec la raréfaction de l'offre herbacée ou concentrée, la part des ligneux dans la ration augmente. L'ingestion est d'autant plus élevée que : i) la teneur en fibre est faible et la teneur en azote élevée, teneurs connues pour modifier la digestibilité et l'ingestibitité des rations; ii) l'appétibilité des plantes présentes est élevée, comme l'indique la diminution des quantités ingérées avec la dis- parition des espèces préférées durant le séjour sur une parcelle.

La dégradabilité ruminale de la matière sèche des ligneux montre une activité des microorganismes accrue au mois de mai, vraisemblablement du fait de la forte teneur en azote fermentescible des jeunes pousses des arbustes et de I'herbe. En mars, la consommation de glands entraîne une diminution de la teneur en fibre de la ration qui provoque une baisse durable du $\mathrm{pH}$ ruminal de 1 point. La dégradabilité des ligneux et de la paille traitée est sensiblement réduite.

Bourbouze A (1980) Fourrages 82, 121-144

Demarquilly C, Chenost M (1969) Ann Zootech $18,419-436$

Tableau I. Caractéristiques de la ration ingérée et dégradabilité des aliments ligneux.

Novembre Décembre Mars Mai

Composition botanique de la ration ingérée

(\% MS)

Bruyère

Chêne

59

27

Autres ligneux 14

Herbacées 0

Glands

0

$\begin{array}{rrr}95 & 0 & 39 \\ 0 & 0 & 17 \\ 5 & 1 & 7 \\ 0 & 32 & 37 \\ 0 & 67 & 0\end{array}$

Quantité ingérée

$\begin{array}{lcccc}\text { MS }(g / 1) & 1300 & 490 & 1340 & 1100 \\ \text { MAT (\%) } & 7 & 6 & 10 & 9 \\ \text { NDF (\%) } & 56 & 58 & 11 & 54 \\ \text { MAT/NDF } & 0,12 & 0,10 & 0,88 & 0,16\end{array}$

Dégradabilité $48 \mathrm{~h}$ in sacco (\%)

$\begin{array}{lcccc}\text { Bruyère } & 40,6 & 41,2 & 29,7 & 47,8 \\ \text { Chêne } & 38,8 & - & 31,7 & 54,6 \\ \text { Paille } \mathrm{NH}_{3} & 58,1 & 71,1 & 36,6 & 53,7\end{array}$

